Nevşehir Bilim ve Teknoloji Dergisi TARGíD Özel Sayı 79-88 2016

DOI: 10.17100/nevbiltek.210969

URL: http://dx.doi.org/10.17100/nevbiltek.210969

\title{
Fındık Arz Fonksiyonu Tahmin Modeli: Türkiye Üzerine Ekonometrik Bir Uygulama
}

\author{
Mehmet Arif Şahinli ${ }^{1 *}$ Ahmet Özçelik ${ }^{2}$ \\ ${ }^{1}$ Ankara Üniversitesi, Ziraat Fakültesi, Tarım Ekonomisi Bölümü, Ankara \\ ${ }^{2}$ Ankara Üniversitesi, Ziraat Fakültesi, Tarım Ekonomisi Bölümü, Ankara
}

Öz

Uluslararası Gıda ve Tarım Örgütü (Food and Agriculture Organization: FAO)'nun 2012 yılı verilerine göre, Türkiye findık üretimi ve ihracatında lider ülke konumundadır. Türkiye'de üretilen toplam findığın payı dünya toplam findık üretimi içerisinde \%72'dir. Bu göstergeler, Türkiye'nin findık üretiminde ne kadar önemli bir ülke olduğunu göstermektedir.

Fındık üretimini etkileyen çeşitli dışsal faktörler bulunmaktadır. Bu çalışmada, 2000-2014 yılları arasında yer alan çeşitli kurumlara ait ikincil veriler kullanılmıştır. Bu verilerden hareketle, Türkiye için findık arz fonksiyonu tahmin modeli elde edilmesinde Almon modeli sınanmıștır.

Anahtar Kelimeler: Almon Modeli, Gecikmesi Dağıtılmış Model, Fındık Üretimi, Fiyat, Türkiye.

\section{Hazelnut Supply Function Prediction Model: An Econometric Applicaton For Turkey}

\section{Abstract}

According to the International Food and Agriculture Organization (FAO), Turkey is the leading country in the production and export in 2012. The share of total hazelnut production in Turkey in total world hazelnut production is $72 \%$. These indicators in Turkey's hazelnut production shows how important is a country.

There are several external factors that affect the production of hazelnuts. In this study, the secondary data belonging to various institutions will be used between 2000-2014. In the light of these data, the yield of nuts in Turkey for its predictions various econometric models through inspection will attempt to demonstrate the best fit model. Due to an Almon model obtained from the study, nuts yield estimation can be made for future years.

Keywords: Almon model, Distributed-Lag Model, Hazelnut Production, Price, Turkey.

* e-mail: sahinliarif@gmail.com 


\section{Giriş}

Fındık önemli bir ürün olarak Türkiye tarımında yerini almıştır. Bu bağlamda, Türkiye'nin dünyada lider olduğu ürünlerin başında yerini almıştır. 2012 yılı verilerine göre, Türkiye üretimi 660.000 ton ve dünya üretimi 914.000 tondur. Bu verilere göre, Türkiye dünya findık üretiminde $\% 72$ gibi önemli bir orana sahiptir. (FAO, 2015).

Türkiye findık üretiminde en düşük üretimini 1991 yılında 315.000 ton ile gerçekleştirirken en yüksek üretimini 2008 yılında 800.791 ton olarak gerçekleştirmiştir. 2004 yılındaki üretim değeri 1990 y1lındaki üretim değerinden 25.000 ton daha azdır. 2004 yılından itibaren fındık üretim miktarı ciddi bir artış trendi yakalamış ve 2008 yılında en yüksek üretim değerine ulaşılmıştır. 2008 y1lından itibaren üretimde önemli bir düşüş trendi gözlemlenmiş ve 2011 yllındaki üretim değeri 430.000 ton civarına gerilemiştir. 2011 yılındaki üretim değeri 2008 yılındaki üretim değerinin neredeyse iki katı kadar gerilemiştir. 2011 yılından sonra findık üretiminde yeniden bir toparlanma yakalanmış ve 1993 yllındaki üretim değerinin iki katına ulaşmıştır.

Fındık tarımsal bir ihracat ürünü olarak Türkiye için potansiyel bir gelir kaynağı olarak önemini korumaktadır. 1990-2011 yılları arasında Türkiye'de findık ihracat miktar (ton) ve değer (1000 US\$) olarak verilmiştir. 1990=100 bazlı olarak findık ihracat miktarı (ton) ve değerleri (1000 US\$) hesaplanmıştır. Bu noktada, 1990 yılına göre 2011 yllında findık ihracat miktarı \%8.98 oranında azalma göstermiş olup, findık ihracat değeri \%128.62 oranında artmıştır. Fındık ihracat miktarı 2000 yılında 112.129 ton ile en düşük değerinde iken 1995 yılında 185.158 ton ile en yüksek miktarına ulaşmıştır. 1995 yılından sonra 2001 yılı harị̧ findık ihracat miktarı en yüksek değeri yakalayamamıştır. Türkiye findık ihracat değerleri (1000 US\$) olarak 1990-2011 yılları arasında incelenmiştir. 1990 yılına göre 2011 yılında findık ihracat değeri (1000 US\$) \%128.62 oranında artmıştır. Bu artışların etkisi fındık fiyatı ve döviz kuru artışına bağlanabilir (Tablo 1).

Tablo 1. Türkiye Fındık İhracat miktarı ve Değerleri, 1990=100 Bazlı Değişim Oranları, 1990-2011

\begin{tabular}{|c|c|c|c|c|}
\hline \multirow[b]{2}{*}{ Yıl } & \multicolumn{4}{|c|}{ İhracat } \\
\hline & Miktar (Ton) & $\%$ & Değer (1000 US\$) & $\%$ \\
\hline 1990 & 160.759 & & 455.528 & \\
\hline 1991 & 129.016 & $-19,75$ & 364.772 & $-19,92$ \\
\hline 1992 & 133.119 & $-17,19$ & 344.895 & $-24,29$ \\
\hline 1993 & 143.886 & $-10,50$ & 423.618 & $-7,01$ \\
\hline 1994 & 133.841 & $-16,74$ & 508.823 & 11,70 \\
\hline 1995 & 185.158 & 15,18 & 589.644 & 29,44 \\
\hline 1996 & 143.282 & $-10,87$ & 442.941 & $-2,76$ \\
\hline 1997 & 138.248 & $-14,00$ & 621.289 & 36,39 \\
\hline 1998 & 136.558 & $-15,05$ & 578.057 & 26,90 \\
\hline 1999 & 120.629 & $-24,96$ & 442.720 & $-2,81$ \\
\hline 2000 & 112.129 & $-30,25$ & 366.737 & $-19,49$ \\
\hline 2001 & 174.728 & 8,69 & 486.086 & 6,71 \\
\hline 2002 & 157.595 & $-1,97$ & 361.003 & $-20,75$ \\
\hline 2003 & 136.648 & $-15,00$ & 409.229 & $-10,16$ \\
\hline 2004 & 134.557 & $-16,30$ & 737.370 & 61,87 \\
\hline 2005 & 131.770 & $-18,03$ & 1.207 .482 & 165,07 \\
\hline 2006 & 158.583 & $-1,35$ & 726.668 & 59,52 \\
\hline 2007 & 140.117 & $-12,84$ & 657.223 & 44,28 \\
\hline
\end{tabular}




\begin{tabular}{llccc}
$\mathbf{2 0 0 8}$ & 134.663 & $-16,23$ & 778.965 & 71,00 \\
$\mathbf{2 0 0 9}$ & 128.702 & $-19,94$ & 710.844 & 56,05 \\
$\mathbf{2 0 1 0}$ & 149.605 & $-6,94$ & 892.254 & 95,87 \\
$\mathbf{2 0 1 1}$ & 146.322 & $-8,98$ & 1.041 .429 & 128,62 \\
\hline
\end{tabular}

Kaynak: Fao

Türkiye findık ihracat miktar (ton) ve değerleri (1000 US\$) 2000-2011 yılları arası için aşağıda verilmiştir. Fındık ihracat miktarlarının dağılımı verilen yıllara arasında yatay bir seyir izlemiş olup 200.000 ton sınır değerini aşamamıştır. Buna paralel olarak, fındık ihracat değerleri 2005 yılında peak noktasına ulaşmıştır. 2011 yılında fındık ihracat değerinin 2005 yılındaki değerinden düşük çıktığı gözlenmiştir (Şekil 1).

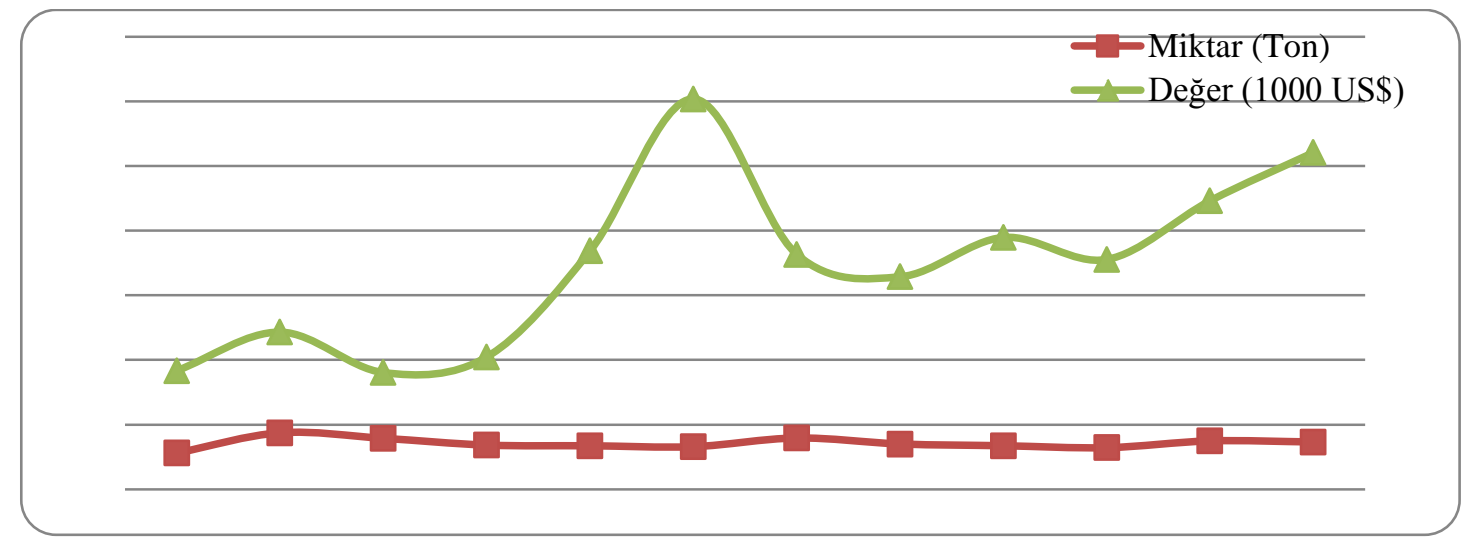

Şekil 1. Türkiye Fındık İhracat miktarı ve Değerleri, 2000-2011

Fındık toplu meyvelik alanı 2000=100 bazlı olarak incelenmiş 2014 yılında toplu meyvelik alanı 2000 yılına göre \%27.60 oranında bir artış göstermiştir. 2004 yılından itibaren incelendiğinde findık alanında bir artış trendi gözlenmiş ancak 2009 yılında \%20'nin altına düşerek \%16.99 gibi bir orana düşmüştür. 2001-2003 y1lları arasında fındık alanında önemli artışlar gerçekleşmemiştir. Bu yıllar arasında meyve veren yaştaki ağaç sayısında yavaş bir artışın olduğu gözlenebilmektedir (Tablo 3).

Tablo 2. Fındığa Ait Bazı Önemli İstatistiki Göstergeler, 2000-2014, Türkiye

\begin{tabular}{|c|c|c|c|c|c|c|}
\hline & & Toplu & & İhracat & & \\
\hline Yıl & ÇEF & $\begin{array}{l}\text { Meyveliklerin } \\
\text { Alanı (dekar) }\end{array}$ & $\begin{array}{c}2000=100 \\
(\%)\end{array}$ & $\begin{array}{c}\text { Ortalama Fiyat } \\
\text { (Dolar/Kental) }\end{array}$ & $\begin{array}{c}2000=100 \\
(\%)\end{array}$ & $\begin{array}{c}\text { Meyve Veren Yaşta } \\
\text { Ağaç Sayısı }\end{array}$ \\
\hline 2000 & 1,04 & 5.495 .000 & & 334,76 & & 282.970 .000 \\
\hline 2001 & 1,34 & 5.550 .000 & 1,00 & 248,84 & $-25,67$ & 285.000 .000 \\
\hline 2002 & 1,67 & 5.600 .000 & 1,91 & 233,45 & $-30,26$ & 289.000 .000 \\
\hline 2003 & 1,89 & 6.000 .000 & 9,19 & 409,93 & 22,46 & 303.900 .000 \\
\hline 2004 & 2,50 & 6.500 .000 & 18,29 & 797,64 & 138,27 & 325.000 .000 \\
\hline 2005 & 3,97 & 6.550 .000 & 19,20 & 816,94 & 144,04 & 321.500 .000 \\
\hline 2006 & 3,76 & 6.662 .262 & 21,24 & 507,68 & 51,66 & 337.380 .483 \\
\hline 2007 & 3,79 & 6.638 .174 & 20,80 & 766,83 & 129,07 & 357.948 .270 \\
\hline 2008 & 3,78 & 6.631 .928 & 20,69 & 481,59 & 43,86 & 340.285 .551 \\
\hline
\end{tabular}


Şahinli MA., Özçelik A.

$\begin{array}{llllccl}\mathbf{2 0 0 9} & 3,87 & 6.428 .669 & 16,99 & 630,53 & 88,35 & 347.414 .378 \\ \mathbf{2 0 1 0} & 4,23 & 6.678 .649 & 21,54 & 633,97 & 89,38 & 356.761 .858 \\ \mathbf{2 0 1 1} & 5,38 & 6.969 .643 & 26,84 & 792,47 & 136,73 & 354.713 .121 \\ \mathbf{2 0 1 2} & 5,47 & 7.014 .067 & 27,64 & 581,17 & 73,61 & 348.781 .578 \\ \mathbf{2 0 1 3} & 5,06 & 7.021 .437 & 27,78 & 740,33 & 121,15 & 348.563 .209 \\ \mathbf{2 0 1 4} & 9,38 & 7.011 .413 & 27,60 & 1237,22 & 269,59 & 349.189 .710\end{array}$

Kaynak: TÜíK

[1] çalışmasında, 1985-1997 yılları arasında pamuk üretimi ve pamuğu açıklayan bir değişken olan fiyat üzerinde çalışmıştır. Fiyatın gecikmeli değerlerinin üretime olan etkileri Koyck ve Almon yaklaşımı ile incelenmiştir.

Gecikmesi dağıtılmış modellerin çözümlenmesi aşamasında bu çalışmada Almon modeli kullanılmıştır. Bu model, findık üzerine uygulanmıştır. İki ayrı fiyat değişkeninin, toplu meyveliklerin alanı üzerinde nasıl bir etki yarattığı denenmiştir. Bu fiyatlar şunlardır: Yurtiçi findık fiyatı (TL), çiftçinin eline geçen fiyat indeksi ile deflate edilerek fiyat serisi oluşturulmuştur. Ayrıca, ABD doları (\$) cinsinden findık ihraç fiyatı ile döviz kurunun çarpımıyla diğer bir fiyat serisi de kullanılmıştır. Değişkenlere ait veri dönemi 2000-2014 yıllarını kapsamaktadır. Gecikmesi dağıtılmış modellerin tahmininde direkt en küçük karelerin uygulanabilmesi sıkıntı yaratmaktadır. Bunun için bu çalışmada Shirley Almon’un önerdiği Almon modeli denenmiştir.

$\mathrm{Bu}$ çalışmada, İki ayrı fiyat değişkeninin, toplu meyveliklerin alanı üzerinde nasıl bir etki yarattığı Almon modeli ile sınanmaya çalışılmıştır. Çalışmanın giriş bölümünde fındık üretimi ve ihracatı ile ilgili bilgiler verilmiştir. İkinci bölümde materyal ve metot hakkında bilgi verilmiş, üçüncü bölümde araştırmadan elde edilen bulgular yorumlanmıştır. Son bölümde ise, araştırma sonuçları ve ilgili çalı̧̧alar kıyaslanmış ve öneriler sunulmuştur.

\section{Materyal ve Metot}

Gecikmesi dağıtılmış modeller, dinamik modellerden bağımlı değişkenin sadece gecikmeli bağımsız değişkenler tarafindan etkilendiği modeller olup, doğrusal ya da doğrusal olmayan formda olabilir. Bu bağımlı değişkendeki değişmeler bağımsız değişkenlerin bir devre gecikmeli değeri tarafindan açıklanabilmektedir. Ancak bu gecikme sayıları ya da uzunlukları birden büyük olarak da belirlenebilir. Bağımsız değişkenlerin seçimi ve fit modelin uygulanabilirliği klasik modeller için mevcuttur. Ancak, gecikmesi dağıtılmış modeller için hangi bağımsız değişkenin gecikmeli değerinin modelde yer alması ve ilgili değişkenlerin gecikme uzunluklarının ne kadar olabileceği belirlenmelidir [2].

Fındık fiyatları, Çiftçinin Eline Geçen Fiyat (ÇEF) indeks ve toplu meyveliklerin alanı (dekar) Türkiye İstatistik Kurumu (TÜIK) verilerinden, ihracat ortalama fiyat (dolar/kental) Karadeniz İhracatçı Birlikleri (KİB) verilerinden alınmıştır. Yurtiçi findık fiyatı (TL), çiftçinin eline geçen fiyat indeksi ile deflate edilerek fiyat serisi oluşturulmuştur. Ayrıca, ABD doları (\$) cinsinden findık ihraç fiyatı ile döviz kurunun çarpımıyla diğer bir fiyat serisi de kullanılmıştır. Araştırmanın yapısına uygun hale getirmek için analiz aşamasında ham verilerden hareketle çeşitli dönüştürmeler yapılmıştır. Veri dönemi 2000-2014 arasındaki yıllara aittir [3 ve 4]. 
Belirlenen uygun gecikme uzunluğu k olursa, buna paralel olarak parametre sayısının gecikme uzunluğu sayısının bir fazlası olacaktır. Modelin parametrelerinin tahmini sırasında, gözlem değerleri gecikmeler nedeniyle gözlem eksi gecikme kadar ortaya çıkacaktır. Gecikme uzunluğunun artmasına paralel olarak gözlem sayısında kayıp ortaya çıkacaktır. Daha da ötesi tahminde kullanılamayan kayıp gözlemler sonucunda tahminler de kötü çıkabilir. Bağımsız değişkenin şimdiki ve geçmiş değerleri arasında yüksek korelasyon çıkması nedeniyle çoklu doğrusal bağlantı sorunu ortaya çıkabilir. Çoklu doğrusal bağlantı sorununun çözümü aşamasında bazı değişkenlerin modelden çıkarılması ve yenilerinin denenmesi ile sorun çözülebilir.

Gecikmesi dağıtılmış modellere direkt olarak En küçük kareler yönteminin uygulanması sakıncalar yaratmaktadır. En önemli problemlerden birisi, yeterli serbestlik derecesinin bulunmayışıdır. Diğeri ise, çoklu bağlantı problemidir. Gecikmenin nedenleri arasında, psikolojik nedenler, teknolojik nedenler ve kurumsal nedenler ortaya çıkmaktadır. İnsanlar bir fiyat veya gelir artışı karşısında alışkanlıklarını bir süre devam ettirme eğiliminde olabilir. Yeni fiyat düşüşü veya yeni bir buluş beklentisiyle kişiler alım yapmayı erteleyebilir. Yapılan sözleşmelere uyma zorunluluğu firma kararlarını değiştirmede süre gerektirebilir.

Gecikmesi dağıtılmış modellerin tahmininde direkt en küçük karelerin uygulanabilmesi sıkıntı yaratmaktadır. Bunun için bu çalışmada Shirley Almon’un önerdiği Almon modeli denenecektir. Almon modeli, gecikme yapısı açısından Koyck modeline göre daha üstün özelliğe sahiptir. Gecikmesi sonlu dağıtılmış model:

$Y_{t}=\propto+\beta_{0} X_{t}+\beta_{1} X_{t-1}+\beta_{2} X_{t-2}+\ldots+\beta_{k} X_{t-k}+u_{t}$ şeklinde yazılabilir.

Bunu şu şekilde de ifade etmek mümkündür:

$$
Y_{t}=\propto+\sum_{i=0}^{k} \beta_{i} X_{t-i}+u_{t}
$$

Almon modeli oluştururken Weierstrass teoreminden yararlanmış ve $\beta_{i}$ 'nin gecikme uzunluğu i'nin uygun dereceden bir çok terimli ile yaklaşık olarak bulunabileceğini varsaymaktadır [5]. Tartılar modelin polinom şeklini almasına göre tanımlanmaktadır.

Örneğin gecikme dizinine göre,

$\beta_{i}=a_{0}+a_{1} i+a_{2} i^{2}$ Polinom ikinci dereceden ya da i'nin kareli şeklindeki çok terimlisidir. Daha genel ifade ile,

$\beta_{i}=a_{0}+a_{1} i+a_{2} i^{2}+\ldots+a_{m} i^{m}$ i'nin m'inci dereceden çokterimlisidir.

$\beta^{\prime}$ ların ikinci dereceden çok terimliye uygun olduğu varsayımı altında, Almon dizininin işleyişini şu şekilde açıklayabiliriz:

$$
Y_{t}=\propto+\sum_{i=0}^{k}\left(a_{0}+a_{1} i+a_{2} i^{2}\right) X_{t-i}+u_{t}
$$

$X_{t-i}$ 'leri parantez içine dağıttığımızda,

$$
Y_{t}=\propto+a_{0} \sum_{i=0}^{k} X_{t-i}+a_{1} \sum_{i=0}^{k} i X_{t-i}+a_{2} \sum_{i=0}^{k} i^{2} X_{t-i}+u_{t}
$$


elde edilir.

Aşağıdaki tanımları yapalım:

$$
\begin{aligned}
& Z_{0 t}=\sum_{i=0}^{k} X_{t-i} \\
& Z_{1 t}=\sum_{i=0}^{k} i X_{t-i} \\
& Z_{2 t}=\sum_{i=0}^{k} i^{2} X_{t-i}
\end{aligned}
$$

Almon dizinini artık şöyle düzenleyebiliriz:

$$
Y_{t}=\propto+a_{0} Z_{0 t}+a_{1} Z_{1 t}+a_{2} Z_{2 t}+u_{t}
$$

Almon dizini, artık $Z$ değişkenlerine göre regresyonu elde edilir. Bu modeli Sıradan en küçük kareler yöntemi ile tahmin edebiliriz Gecikmesi dağıtılmış modellerin tahmini en küçük kareler (EKK) yöntemi kullanılarak yapılır [6]. Bu noktada, $\alpha$ ve $a_{i}$ 'nin elde edilen tahminleri klasik doğrusal regresyon modelinin varsayımlarını yerine getirecektir.

a'ları tahmin ettikten sonra, Gecikmesi sonlu dağıtılmış modeldeki ß'ların tahmini şöyle olacaktır:

$$
\begin{gathered}
\widehat{\beta_{0}}=\hat{a}_{0} \\
\widehat{\beta_{1}}=\widehat{a}_{0}+\hat{a}_{1}+\hat{a}_{2} \\
\widehat{\beta_{2}}=\hat{a}_{0}+2 \hat{a}_{1}+4 \hat{a}_{2} \\
\ldots \ldots \ldots \ldots \ldots \\
\widehat{\beta_{k}}=\widehat{a}_{0}+k \widehat{a}_{1}+k^{2} \widehat{a}_{2} \text { elde edilir. }
\end{gathered}
$$

Almon tekniğinin uygulama aşamaları şu şekilde özetlenebilir:

1.Gecikmenin en uzak uzunluğu olan k sayısı önceden belirlenmelidir. Bunun için Davidson ve MacKinnon önerisi olan ilk önce gecikme uzunluğunu belirlemek olmalıdır [7]. Gecikme uzunluğu için Akaike Information Criterion (AIC) ya da Schwartz Bayesian Criterion (SBC) biçimsel sınamalar kullanılabilir [8].

2.Gecikme uzunluğu (k) belirlenir ve daha sonra çokterimli derecesi (m) saptanır. Çokterimli derecesi, $\beta_{i}$ 'yi i'ye bağlayan eğrinin bükülme noktaları sayısından en az bir fazla olmalıdır [9].

3.m ve $\mathrm{k}$ belirlendikten sonra Z'leri oluşturmak artık mümkündür.

\section{Bulgular}

Almon tekniğini açıklamak amacıyla, 2000-2014 dönemi Türkiye'de tarım kesiminde toplu meyveliklerin alanı (dekar) ve deflate edilmiş Yurtiçi findık fiyatı (TL) ile ABD doları (\$) cinsinden findık ihraç fiyatı ile döviz kurunun çarpımıyla diğer bir fiyat serisi kullanılmıştır. 
Açıklayıcı amaçlar çerçevesinde, toplu meyveliklerin alanı (dekar) içinde bulunulan yıl ve önceki yıllara bağlı olduğu düşüncesi ile gecikmesi dağıtılmış model aşağıdaki gibi oluşturulmuştur.

$$
Y_{t}=\propto+\beta_{0} X_{t}+\beta_{1} X_{t-1}+\beta_{2} X_{t-2}+\ldots+\beta_{k} X_{t-k}+u_{t}
$$

Gecikmesi dağıtılmış modelde;

$Y_{t}:$ toplu meyveliklerin alanı (dekar)

$X_{t}$ : Yurtiçi findık fiyatı $(\mathrm{TL} / \mathrm{Kg})$

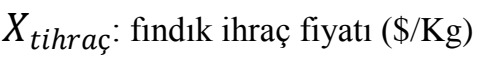

Çalışmada, iki ayrı fiyat serisinin toplu meyveliklerin alanına olan etkisi iki ayrı model çerçevesinde incelenmiştir. Bunun için de iki ayrı model için AIC değerleri hesaplanmış ve bu sonuçlar Tablo 3'de verilmiştir.

Tablo 3. Akaike Information Criterion (AIC)’ne Göre Gecikme Uzunlukları

\begin{tabular}{ccc}
\hline $\mathbf{k}$ & & AIC \\
& Yurtiçi Fındık Fiyatı (TL/Kg) & Fındık İhraç Fiyatı (\$/Kg) \\
$\mathbf{1}$ & -10.052 (Düzeyde) & -53.164 (1. Sıra fark) \\
\hline
\end{tabular}

Gecikme dizinine göre, $\beta_{i}=a_{0}+a_{1} i+a_{2} i^{2}$ Polinom ikinci dereceden ya da i'nin kareli şeklindeki çok terimlisi ile yaklaşık olarak belirtilebileceğini varsayalım. $\mathrm{Bu}$ durumda, Almon dizinini artık şöyle düzenleyebiliriz:

$$
Y_{t}=\propto+a_{0} Z_{0 t}+a_{1} Z_{1 t}+a_{2} Z_{2 t}+u_{t}
$$

Tablo 4. Fındık İçin Hesaplanmış Modellerin Parametre Tahminleri

\begin{tabular}{ccc} 
Değişkenler & \multicolumn{2}{c}{ Almon Modeli Hesaplanan } \\
& Model 1 & Model 2 \\
Sabit terim & 7344227 & 5854970 \\
$\mathbf{t}$ & 14.0975 & 33.6473 \\
$\boldsymbol{P}_{\boldsymbol{t}}$ & -341042.8 & 133.9068 \\
$\mathbf{t}$ & -1.6311 & 2.7879 \\
$\boldsymbol{P}_{\boldsymbol{t}-\mathbf{1}}$ & & 131.8154 \\
$\mathbf{t}$ & & 2.8232 \\
\hline
\end{tabular}

\section{Model 1 iccin;}

$$
Z_{0 t}=\sum_{i=0}^{1} X_{t-i}=\left(X_{t}+X_{t-1}\right)
$$

Böylece oluşturulan $Z$ değişkenlerine göre, $Y$ ve $Z$ verilerini kullanarak aşağıdaki regresyona ulaşabiliriz: 
$\hat{Y}=7344227-341042,8 Z_{0 t}$

Sh (520957.6) (209086.6)

t: (14.09755) (209086.6)

düzeltilmiş $R^{2}=0.113$

$\mathrm{Bu}$ tahmin değerlerinden hareketle, tahmin edilmiş olan a katsayılarını kullanarak, $\widehat{\beta_{0}}=\widehat{a}_{0}$ bu ilişki kullanılarak aşă̆ıdaki $\beta$ katsayılarını şu şekilde tahmin etmek mümkündür:

$\beta_{0}=a_{0}=-341042.8$

Böylelikle $Y_{t}=\propto+\beta_{0} X_{t}+\beta_{1} X_{t-1}+\beta_{2} X_{t-2}+\ldots+\beta_{k} X_{t-k}+u_{t}$ denklemine karşıllık gelen gecikmesi dağıtılmıs modellerin tahmin edilmiş parametreleri Tablo 4 'de verilmiştir.

$\hat{Y}=7344227-341042,8 X_{0 t}$

Sh (520957.6) (209086.6)

t: $\quad(14.09755)(-1.631107)$

Eşitlik (1)'de verilen modelde $\propto$ katsayısı anlamlı iken $\beta_{0}$ katsayısının anlamsızlığı dikkat çekmektedir. Böyle bir eksi işareti anlam ifade etmediğinde $\beta_{0}=0$ sınırlama getirilir ve gecikme yapısı yeniden tahmin edilebilir.

\section{Model 2 icin;}

$$
\begin{gathered}
Z_{0 t}=\sum_{i=0}^{2} X_{t-i}=\left(X_{t}+X_{t-1}\right) \\
Z_{1 t}=\sum_{i=0}^{2} i X_{t-i}=\left(X_{t-1}+2 X_{t-2}\right)
\end{gathered}
$$

Böylece oluşturulan $\mathrm{Z}$ değişkenlerine göre, $\mathrm{Y}$ ve $\mathrm{Z}$ verilerini kullanarak aşağıdaki regresyona ulaşabiliriz:

$$
\begin{aligned}
& \hat{Y}=5854970+133.9068 Z_{0 t}-2.091445 Z_{1 t} \\
& \text { Sh (174009.9) (48.03080) (46.68863) } \\
& \text { t: } \quad(33.64734)(2.787937) \quad(-0.044796)
\end{aligned}
$$

düzeltilmiş $R^{2}=0.623$

$\mathrm{Bu}$ tahmin değerlerinden hareketle, tahmin edilmiş olan a katsayılarını kullanarak, $\widehat{\beta_{0}}=\widehat{a}_{0}$ ve $\widehat{\beta_{1}}=\widehat{a}_{0}+\widehat{a}_{1}$ bu ilişki kullanılarak aşağıdaki $\beta$ katsayılarını şu şekilde tahmin etmek mümkündür:

$$
\begin{gathered}
\beta_{0}=a_{0}=133.9068 \\
\beta_{1}=a_{0}+a_{1}=133.9068-2.091445=131.8154
\end{gathered}
$$

Böylelikle $Y_{t}=\alpha+\beta_{0} X_{t}+\beta_{1} X_{t-1}+\beta_{2} X_{t-2}+\ldots+\beta_{k} X_{t-k}+u_{t}$ denklemine karşıllk gelen gecikmesi dağıtılmış modellerin tahmin edilmiş parametreleri Tablo 4 'de verilmiştir.

$\hat{Y}=5854970+133.9068 X_{t}+131.8154 X_{t-1}$ 
Sh (174009.9) (48.03080) (46.68863)

$\mathrm{t}: \quad(33.64734)(2.787937) \quad(2.823287)$

Eşitlik (2)'de verilen modelde $\propto$ katsayısı ve $\beta_{0}, \beta_{1}$ katsayıları anlamlı çıkmıştır. Sonuç olarak, bu modelde Almon yöntemi çeşitli gecikme yapılarını içeren esnek bir yöntem sunmaktadır. Modelden gecikmeli fiyatların toplu fındık alanı üzerinde etkisi azalan bir etkiye sahiptir. Bu etkinin bir yıl sürdüğü gözlemlemiştir.

\section{Tartışma ve Sonuç}

Türkiye fındık üretiminde en düşük üretimini 1991 yılında 315.000 ton ile gerçekleştirirken en yüksek üretimini 2008 yılında 800.791 ton olarak gerçekleştirmiştir. 2011 yılından sonra findık üretiminde yeniden bir toparlanma yakalanmış ve 1993 yılındaki üretim değerinin iki katına ulaşmıştır.

Fındık tarımsal bir ihracat ürünü olarak Türkiye için potansiyel bir gelir kaynağı olarak önemini korumaktadır. 1990 yılına göre 2011 yılında fındık ihracat miktarı \%8.98 oranında azalma göstermiş olup, fındık ihracat değeri \%128.62 oranında artmıştır. Bu artışların etkisi fındık fiyatı ve döviz kuru artışına bağlanabilir. Fındık ihracat değerleri 2005 yılında zirve noktasına ulaşmıştır. 2014 yılında toplu meyvelik alanı 2000 yılına göre \%27.60 oranında bir artış göstermiştir.

Toplu fındık alanı-fiyat ilişkisinin, gecikmesi dağıtılmış modellere uygun olup olmadığı belirlenmek istenmiştir. Bu bağlamda, değişkenler arasındaki ilişkinin korelasyon katsayısı 0.77 olarak elde edilmiştir. Ürün fiyat ilişkisinde korelasyon katsayıları ile ilgili olarak [10] tütün için 0.47, [11] buğday için 0.64 değerlerini bulmuştur.

Bu çalışmada, 2000-2014 dönemi Türkiye'de tarım kesiminde toplu meyveliklerin alanı (dekar) ve deflate edilmiş Yurtiçi fındık fiyatı (TL) ile ABD doları (\$) cinsinden findık ihraç fiyatı ile döviz kurunun çarpımıyla diğer bir fiyat serisi kullanılmıştır.

Almon tekniğini açıklamak amacıyla, açıklayıcı amaçlar çerçevesinde, toplu meyveliklerin alanı (dekar) içinde bulunulan yıl ve önceki yıllara bağlı olduğu düşüncesi ile gecikmesi dağıtılmış modeller iki ayrı fiyat serisi için oluşturulmuştur. Fındığın toplu meyveliklerin alanı (dekar) ve fiyat serileri ilişkisini açıklamada iki ayrı Almon modeli denenmiş model 2'nin daha uygun olduğu görülmüştür.

Almon modelinin analizi için, incelenen verilerden ABD doları (\$) cinsinden findık ihraç fiyatının gecikmeli değeri AIC kriterine göre hesaplanarak, gecikme sayısı 1 olarak saptanmıştır. Bu gecikme uzunluğu kullanılarak incelenen dönemde toplu findık alanı ile fiyatı için gecikmesi dağıtılmış model oluşturularak regresyon analizi yapılmıştır.

Modelleri oluşturmadan önce, gecikme uzunluğunun belirlenmesi aşamasında AIC değerlerine bakılmıştır. Bu modellerde kullanılan seriler için elde edilen AIC değerlerinin en küçük olması ve bu noktada bu en küçük AIC değerine sahip gecikme maksimum gecikme olarak kabul edilmiştir. Model 1'de kullanılan Yurtiçi fındık fiyatı (TL) değişkeni düzeyde durağan I(0) iken, Model 2'de kullanılan ABD doları (\$) cinsinden fındık ihraç fiyatı birinci sıra fark durağan I(1) olarak bulunmuştur. Tabii bu noktada her iki fiyatın cari olarak kullanılmaması modellerin anlamlılı̆̆ını daha da pekiştirmiştir. 
Sonuç olarak tam rekabet piyasasında oluşan findık fiyatlarının, toplu meyveliklerin alanını belirlemede etkisinin yüksek olduğu söylenebilir. Ancak, her iki fiyat serisine göre hesap edilen Almon modeline göre, ABD doları (\$) cinsinden fındık ihraç fiyatı diğer fiyata göre daha etkili olduğu görülmüştür. Türkiye'de her yıl fındık üreticilerimize bakanlar kurulu kararı ile alan bazlı gelir desteği ödemeleri yapılmaktadır. Destekleme ödemeleri çiftçinin üretim sürecini etkileyecek önemli bir faktör olarak karşımıza çıkmaktadır. Türkiye findık üretiminde dünya'da 1. sırada olan en önemli ülkelerden biridir ve dünya üretiminin \%72'sini gerçekleștirmektedir. Bunun için bu önemli ürüne uluslararası rekabet avantajı kazandırmak ve bu üründen daha fazla katma değer elde etmek için mamul ürün çeşitlendirmesine gidilerek ülkenin tarımsal dış ticaretine önemli katkılar yapması sağlanmalıdır. Ayrıca, üretim planlaması yapılarak üreticiler önemli bir fiyat belirsizliği sorunu yaşamaktan kurtulabilir.

\section{Kaynaklar}

[1] Yurdakul F., "Pamuk Üretimi ile Pamuk Fiyatı Arasındaki İlişkinin Ekonometrik Analizi: KoyckAlmon Yaklaşımı" Çukurova Üniversitesi İktisadi ve İdari Bilimler Fakültesi Dergisi, 8(1): 341-353, 1998.

[2] Güriş S., Çağlayan E., "Ekonometri Temel Kavramlar", Der yayınları, İstanbul, 2010

[3] Kib (2014). Karadeniz İhracatçı Birlikleri Genel Sekreterliği. http://www.kib.org.tr/tr/

[4] Tüik (2014). Türkiye İstatistik Kurumu. http://www.tuik.gov.tr

[5] Almon S., "The Distributed Lag Between Capital Appropriations and Expenditures" Econometrica, 33(1):178 - 196, 1965

[6] Tinbergen J., "Long-Term Foreign Trade Elasticities" Metroeconomica, 1(3): 174-185, 1949

[7] Davidson R., MacKinnon J.G., "Estimation and ference in Econometrics". Oxford University Pres, New York: 675-676, 1993

[8] Schwartz G., "Estimating the Dimension of a Model" The Annals of Statistics, 5(2): 461-464, 1978

[9] Gujarati D. N., Basic Econometrics, McGraw-Hill, New York, 1999

[10] Dikmen N., "Koyck - Almon Yaklaşımı İle Tütün Üretimi ve Fiyat İlişkisi" Çukurova Üniversitesi Sosyal Bilimler Dergisi 15(2), 153-168, 2006

[11] Özçelik A., Özer, O., "Koyck Modeliyle Türkiye'de Buğday Üretimi ve Fiyat İlişkisinin Analizi" Tarım Bilimleri Dergisi, 12: 333-339, 2006 